Most contemporary studies of science operate with some notion of scientific specialty communities as the basic units within which science is socially and technically organized. This paper presents a critique of scientific communities as sociological constructs which appear to be largely irrelevant to scientific work. Furthermore, the paper criticizes the prevailing quasi-economic models of such collectives for what appears to be a naive internalism and functionalism compared with the realities of scientific everyday life as they concern scientists themse/ves. It is argued that the arenas of action within which scientific

(laboratory) inquiry proceeds are transepistemic - that is, they in principle include scientists and non-scientists, and encompass arguments and concerns of a 'technical' as well as a 'non-technical' nature. The paper also argues that the transepistemic connection of research is built into scientific inquiry land thereby into the products of research) through the decision criteria invoked in laboratory work. The paper draws upon one year of observation in a scientific laboratory in Berkeley, California, which provides the grounds and the illustrations for the theoretical arguments presented.

\title{
Scientific Communities or Transepistemic Arenas of Research? A Critique of Quasi-Economic Models of Science
}

\author{
Karin D. Knorr-Cetina
}

The Scientific Community as a
Unit of Contextual Organization

Recent studies of scientific laboratories emphasize the methodological and theoretical significance of the research site. ${ }^{1}$ First, the 
site of scientific action offers a unique opportunity to investigate the process of knowledge production, which continues to be a 'black box' to social studies of science. ${ }^{2}$ Second, the few investigations which are by now available all confirm the local, situationally contingent nature of research production, a result of considerable theoretical interest. ${ }^{3}$ The research site begins to emerge from these as a reality sui generis which is constitutive of the characteristic features of science, much as the social situation emerged from microsociological investigations as the locus of social action in general.

Yet it will be clear that a locus of social action is not a naturally bounded unit within which social action is confined. Laboratory selections situated in a locally circumscribed space appear to be simultaneously situated in a field of social relations. The situational contingencies observed in the laboratory are traversed and sustained by relationships which constantly transcend the site of research. What do we know about this contextual aspect of knowledge production, and what can we learn from the direct observation of scientists at work? While research sites have been notoriously neglected in empirical investigations of science, the same cannot be said of more global, contextual structures. In particular, the notion that professional membership groups (called scientific communities) are the relevant units of the social and cognitive organization of science has penetrated into virtually every social study of science.

Most contemporary students of science operate with some notion of specialist communities, even when they dispute other theoretical and methodological orientations and pursue different goals. Thus studies of citation and communication, studies emerging in the wake of questions raised by Kuhn, investigations of the 'social system' of science, and analyses of the social and cognitive institutionalization of scientific disciplines all invoke the notion of a scientific community. ${ }^{4}$ In general, these communities are seen as small social systems with fuzzy borders and internal mechanisms of integration; these systems are frequently circumscribed by a specialty area represented in the scientific literature. ${ }^{5}$ The original merit of Merton's structural-functional sociology of science was to focus attention on the social organization of scientists. Following such guidelines, sociologists of science have generally assumed that scientific communities are the basic organizing units in science. Presumably, much can be learned from investigating the clusters of 
scientists which, by whatever means, come to be associated with a specialty area, provided one asks the proper questions. But are these communities also the units within which scientific work as observed in the laboratory is contextually organized?

In a recent study of communication patterns in a number of research laboratories, Whitley argues that such relatively broad organizational units as specialist communities are largely irrelevant and often unknown to the scientists. Edge has called the "correct definition of a specialty' a meaningless concept and suggested that it be replaced by a radically participant-centred perspective on scientific collectivities. ${ }^{6}$ What, then, are the units of the contextual organization of scientific work which we are to substitute for the notion of specialty groups? In this paper, my strategy in developing an answer to this question will be to start with a theoretical and methodological critique of the concept of scientific communities as currently employed; I will then outline a notion, based on laboratory observations, of transepistemic arenas of research organized in terms of resource-relationships. To respond to the above question, it is necessary but not sufficient to criticize the idea of specialty groups. For if specialty communities were the locus of the social and cognitive organization of scientific work we could consider the observable relationships between scientists and nonspecialists as irrelevant to the production of knowledge. I will argue that ignoring such relationships is radically mistaken, and I will show this by drawing out some peculiar consequences and limitations entailed by the concept of specialty communities. In addition, I will draw upon my own laboratory observations to argue that the transepistemic connections of research (described below) are built into scientific inquiry and must be encompassed by our concept of the contextual organization of knowledge production.

\section{Quasi-Economic Models: From Community Gift-Giving to Community Capitalism}

Strictly speaking, the problem of the contextual organization of scientific action has been posed in terms of two distinct questions: the first refers to units of organization, and has generally been answered by the search for scientific communities; the second refers to the mechanism of integration which characterizes the respective collectivities. Ever since the earliest sociological concep- 
tions of science, answers to this second question have been dominated by economic analogies. The movement of these analogies is interesting in itself: the early postulation of relatively isolated economic mechanisms (such as competition) was replaced by the assumption of a pre-capitalist economy, which was then succeeded by strictly capitalist versions of an economy of scientific production.

Merton was one of the first to use the idea of quasi-economic competition. The idea was developed in his study of struggles over the priority of scientific discoveries, and later refined in his work on the Matthew Effect to mean imperfect competition - that is, that recognition accrues to those who have already established a reputation.?

Explicit use of a pre-capitalist economic model is found in Hagstrom (1965), who grounds the normative functional behaviour of scientists in a mechanism by which creative, scientific achievements are exchanges for a variety of rewards specific to the system. This mechanism of exchange is linked to the idea of giftgiving in a normatively integrated community, rather than to maximizing profits in an antagonistic market. The existence of competition does not interfere with the notion of such community life, for it is competition among achievers for the most highly valued achievements. It has nothing to do with the capitalist appropriation of surplus value or scarce resources. Reiterations of the basic ideas of this model can be found in a variety of other authors, notably Storer (1966), who turns science into a form of l'art pour l'art. Storer combines an archaic economy of exchange with the notion that science is a response to the desire to create, which he grounds in the basic nature of man. ${ }^{8}$

The transition from pre-market exchange to a capitalist market economy of science came ten years later at the hands of Bourdieu (1975). ${ }^{9}$ The scientific field was no longer seen as a community of specialists competing for creative achievement, but the locus of a competitive struggle for a monopoly on scientific credit. The concept of 'credit' must not be confused with the 'recognition' advanced in earlier studies. Recognition was defined as a specific form of reward, and referred to the operation of a system which resembled a psychological stimulus-response situation. Rewards like recognition operate as selective mechanisms to reinforce the kind of behaviour by which they are won. Thus, recognition presumably reinforced the truth-seeking, achievement-oriented behaviour con- 
sidered most essential to the scientific system.

In contrast, credit is defined as symbolic capital acquired by scientific agents through the imposition of technical definitions and legitimate representations of scientific objects on the field. Such capital is composed at once of scientific competence and social authority, and like monetary capital, can be converted into all kinds of resources necessary for the continuation of scientific production. Most important, it is actively pursued by scientific agents through strategies of domination and monopolization directed against other relevant producers in the markets formed by scientific fields and disciplines. While recognition operates as a functional sorter to select norm-fulfilling scientific behaviour in an essentially cooperative universe, thus helping the system to maintain itself, Bourdieu's credit or symbolic capital governs the market in an essentially antagonistic universe. And yet it also advances "the progress of reason', at least in the natural sciences. The scientific producers and clients 'cross-control' each other and thus promote truth - a suggestion first made by Polanyi and adopted by Bourdieu.

No such assumptions are made by Latour and Woolgar, ${ }^{10}$ who propose the notion of credibility, rather than credit, to refer to the reproduction of capital. Scientists invest in the fields and topics which promise the greatest return. The credit they gain from producing a surplus of 'new' information is intended solely for reinvestment, which means that scientists are not interested in truth, nor their subject matter, nor in surplus information per se. Nor are they interested in recognition per se. What is of interest is the acceleration and expansion of the reproductive cycle which produces new and credible information - that is, information for which the costs of raising an objection are as high as possible. Reproduction for the sake of reproduction is the mark of pure, scientific capitalism. ${ }^{11}$

Such economic models of scientific agents have not as yet been pushed to their limits. For example, analyses of the increased role of the state, the partial redistribution of economic surplus, or problems of legitimation and motivation in theories of late capitalism, have yet to be incorporated into any model. The inflation of scientific authority, the movement towards a native, 'appropriate' technology (as opposed to that associated with basic science), and the expansion of science policy, all suggest that such analyses are by no means irrelevant to a theory of science. In general, of course, 
the strength of quasi-economic models of science is in demonstrating similarities between science and social life in other domains; it is not in increasing the complexity of economic theories, or of the mechanisms postulated. Yet the analogy can become overly crude, and oblivious of arguments which have seriously challenged or modified the source model. In the following critique of quasi-economic models of science I will first draw attention to the simplistic concept of man promoted by these models, and then turn to the curious consequences of internalism and orthodox functionalism which prevails even in the most radical version of these models.

\section{The Critique of the Capitalist Market Model of Scientific Communities}

In the classical version of the economic concept of man, homo economicus is a conscious maximizer of profit. S/he is either assumed to have an insatiable appetite for property, or is thought to accumulate for the sake of accumulation. In the first case, we seem to be confronted with an implicit assumption about human nature which suggests that conflicting goals, competition and exploitation are endemic to human society. In the second, individual economic behaviour is a consequence of market requirements which are in turn a consequence of well-known historical developments.

More sophisticated versions of economic man tend toward the latter interpretation, and substitute the idea of 'satisficing' under conditions of limited information for that of rational maximization. ${ }^{12}$ Actors make do with the first satisfactory solution they come across within the limits of a rationality bounded by incomplete information. Even so the model remains individualistic and voluntaristic. It ignores the result of virtually all microsociological inquiries that outcomes are socially accomplished-incontext or interactively negotiated rather than individually calculated. In addition, it ignores that outcomes are often not consciously 'calculated', which renders the idea of 'satisficing' as problematic as that of 'maximizing'. In Bourdieu's theory of social practice, the notion of a habitus (the sum of dispositions to react) acquired in class-specific socialization replaces the idea of individual calculation. ${ }^{13}$ 
However, the outcomes of social interaction cannot be predicted from the properties individuals have acquired. It is common to associate intentionality and reflexivity with individual persons, and to derive from this explanations of social action in terms of individual dispositions and motivations. As Goffman pointed out, in an article called 'The Neglected Situation', the implication of most social research has been that 'social situations do not have properties and a structure of their own, but merely mark ...the geometric intersection of actors bearing particular social attributes'. ${ }^{14}$ In contrast, the study of social action in situ displays social situations as a reality sui generis with a dynamics and organization of its own that cannot be foreseen by participants or students of social action. It is this social dynamics of interaction which precludes individualistic notions of decision making, whether they are based upon the idea of conscious calculation or of subconscious, habitual selection.

Notice that this is not to deny that participants display themselves on occasions as strategic actors. But the degree to which this is the case appears to be itself a function of social practice that is, of the specific occasion including the participants in the situation. In general, of course, the whole range of problems associated with a concept of social action that suits economic theory is not specific to science studies, and science studies are not likely to come up with a solution to a problem which is no concern of theirs. To be sure, some students of science have tried to guard against such problems by locating their analysis on the macrorather than on the micro-level. Thus, they have defined their goal in terms of explaining the system of science rather than of accounting for the behaviour of individual scientists. ${ }^{15}$ Yet to describe a system in terms of accumulation and conversion of capital requires that we assume a corresponding individual behaviour, or specify some mechanisms to explain why the description of the system does not hold similar implications in regard to the units (the scientists) which constitute it. Quasi-economic models of science are continually interpreted in terms of individual interests precisely because a plausible mechanism of this kind has not been provided. In any case, such a mechanism is hard to imagine, since notions which refer to the accumulation, investment and exchange of symbolic capital or credibility have as their referent the respective actions of individuals, and do not describe systems in the first place. Hence we must assume that the capitalist mode of production attributed to scientific communities comes about through the petty but pertinent 
entrepreneurship of individual scientists; that is, through their conscious or habitual interest in the accumulation of symbolic profit, or in the renewal and acceleration of the cycle of capital. And we end up with all the problems that have haunted the economic construct of man ever since it became the calculative heart of major social theories.

But the economic analogy also poses questions which are specific to its application in science studies. The advantage of an analogy is that we bring to bear upon a little-known phenomenon knowledge derived from a similar, but better understood phenomenon. Yet the knowledge transferred has to remain internally consistent, or else the transfer will amount to not much more than a substitution of terms (such as 'symbolic capital' for 'recognition'). In economic theory, the notion of capital is linked to the idea of exploitation defined in terms of the appropriation of surplus value, and to the corresponding concepts of class structure and alienation. Without adequate conception of exploitation and class structure, the capitalist model loses its most distinctive characteristics. But how are we to conceive of exploitation and class structure in scientific fields said to be ruled by capitalist market mechanisms?

Now we can define exploitation in science as the appropriation of the products created by staff scientists by scientists in superior positions, who then accumulate the symbolic benefits from this work. This would require us to distinguish between scientific capitalists and scientific workers in terms of the possession of (symbolic) capital and control over the means of scientific production. The difficulty here is that the possession of such capital and control (as operationally defined by some notion of credit or credibility through publications, citations, or access to laboratory and other resources) is a common - albeit graded - characteristic of everyone to whom the term 'scientist' is usually applied. In order to differentiate between workers and capitalists, we would have to define some level of symbolic capital and classify scientists as belonging to one or the other category depending on whether their share of capital (or control) fell below or above that level. It is hard to see how such a distinction could be anything less than arbitrary.

Part of the difficulty arises from the fact that the notion of symbolic capital is a conceptual composite whose components are neither clearly defined nor assigned unequivocal consequences. For example, control over the means of production in science does not necessarily imply a high amount of professional recognition, and 
those with high scientific authority are not necessarily those who appropriate other scientists' research products. But a greater difficulty is due to the restricted reference of the capitalist market model of science, which continues to promote an internalistic view of science, despite the more or less explicit rejection of such a view in contemporary science studies.

This internalism is no longer due to the once dominant distinction between the social and cognitive elements of science, but to a continuing focus on scientists themselves. Scientific communities have turned into markets in which producers and clients alike are colleagues in a specialty, or related research areas. Normative and functional integration has been replaced by a competitive struggle in the scientific fields with which these markets are identified. Scientists have indeed become capitalists, but they are still treated as though they were isolated in a self-contained, quasi-independent system. Since we cannot define class differences within this system in a justifiable way, we end up with communities of petty capitalists who sustain themselves by somehow exploiting - or not exploiting? - each other. In economic theory, the existence of such community capitalism would certainly be considered a curiosity, in particular since those who provide the actual resources into which symbolic capital must be converted before it can renew itself are conspicuously absent from the picture. In the capitalist model of science these agencies and groups act like an invisible hand, related to nothing and with no official role in the community business. Since this invisible hand appears to have a rather decisive influence not only on the distribution of research money, but also on the very business of our capitalists (in regard to what is researched), its hidden operation is all the more surprising.

My last point of criticism refers more specifically to the unequivocal connection between the status of the information produced by a scientist and her or his access to positions, careers, research money, citations, or recognition, which some capitalist market models of science take for granted. Accordingly, the credibility associated with statements which are as 'hard' as possible (that is, which are as nearly as possible accredited as statements of 'fact') is invested in the above mentioned resources, which are in turn invested in the production of further credible information. Yet the assumption that a career in science is made by producing 'harder facts' and by converting the credibility associated with such products into positions and resources could lead us back directly 
to Kingsley Davis's famous theory of social stratification according to which those who achieve best earn and warrant the better positions in a society. While such a mechanism might indeed be called functional to the achievement of societal goals, decades of sociological research have shown that it does not exist. ${ }^{16}$

To be sure, it is part of the thrust of present quasi-economic models of science to consider power and dominance as inherent to scientific undertakings. Yet by limiting the perspective to scientific communities, by regarding statements accredited as fact as the pivot of scientific endeavours, and by implying that there exists an unequivocal dependence between the credibility-status of the objects produced and resources as well as positions, power and dominance are once again 'functionalized'. They accrue exclusively from the achievement of credible information, and play no role in the game apart from their relevance to the accelerated reproduction of new information.

\section{The Scientist as an Economic Reasoner, or 'Who are the Entrepreneurs?'}

When we look at the laboratory, ${ }^{17}$ we find that at least part of the reasoning which relates to the scientists' practical decisions does incorporate economic notions, and this sort of scientific discourse has undoubtedly lent plausibility to the model of the scientist as (yet another) economic man. Thus, any criticism of a model which implies a petty community capitalism must decide what to make of the economic reasoning found in the everyday discourse of scientists.

Scientists talk about their 'investments' in an area of research, or an experiment. They are aware of the 'risks', 'costs' and 'returns' connected with their efforts, and talk about 'selling' their results to particular journals and foundations. They seem to know which products are in high 'demand', and the areas in which there is nothing to 'gain'. They want to put hot 'products' on the 'market' as quickly as possible and 'earn credit' for them. Does this language reflect an intrusion of economic - more specifically capitalist - mechanisms into a previously non-economic domain? Did these mechanisms develop from a pre-capitalist exchange of gifts into capitalist competition and monopolization between 1965 and 1975 - that is, between Hagstrom's proposal and those of 
Bourdieu and his followers some ten years later? Or do we have here a phenomenon for which alternative and equally plausible interpretations are available?

It seems to me that there are at least two distinct forms of economic reasoning used in the context of laboratory work. Economic notions are frequently employed when scientists talk about their research strategies, when they reflect upon the way research decisions are made. Consider the following comments of a biochemist made during his account of the origin of a major 'discovery' in which he had taken part:

We always calculate our risks, even though we don't know how to calculate. It's just a feel, you know, and I am very good at this by now. Through many years of experience, I can more or less tell what I should drop and what I should pick up on. I think this is a problem with a lot of unsuccessful scientists - they are not dumb, they just work on the wrong things...

Another thing is that, if you are up against terrific competition, there is no sense in struggling. So by now I can gauge these success factors, and my own secret of success is that I work on things that aren't too unlikely to work out ... (9-29/4).

Similar comments can be heard frequently under appropriate circumstances, and some have been published elsewhere. ${ }^{18}$ Scientists will say that they try to limit their interests to the ideas which are likely to be 'most productive as quickly as possible within the frame of facilities at hand', and that this is a process of 'weighing, you know, the probabilities of success' $(9-27 / 9 ; 8-29 / 5)$. To calculate outcomes, weigh alternatives, and make selections according to some prior consideration of consequences is part of reasoned choice - and what scientists do in these comments is that they describe their ways of decision making in terms which invoke rational action. Given the blend of rational and economic discourse in our everyday vocabulary, it is hardly surprising that scientists' reasoning should at times recall the vernacular of businessmen, particularly when accounts of reasoned choice are the topic of conversation.

There is, however, a second and more implicit form of economic reasoning. It occurs, for example, when scientists say that they are not challenged by a problem because the experiments are 'too simple...the work of a technician or a laboratory assistant'; or when they become fascinated by an instrument said to be expensive and rare, and do everything possible to incorporate this instrument 
in their ongoing work; or when they argue at length about the journal in which to publish their material, and display the usual concern about the rank order of authors. In the most general sense, the economics implicit in this reasoning lies in its preoccupation with value. Whether the subject is an experiment too simple to warrant a scientist's involvement, or using a scarce instrument in place of a common one, or publishing a paper in a renowned rather than a secondary journal, the concern is with maintaining, increasing or displaying value.

Notice, however, that what is at stake here is not the value of some product, but the value of the scientists themselves. The string of institutions and positions we find in curricula vitae provides an updated balance sheet for a scientist, not for a product. The quality at issue in choosing an experiment, a piece of apparatus or a journal is the quality of the scientist. And the success to which scientists most often refer is their own. If we want to use the economic metaphor, we can say that scientists' concern with their investments and returns, with the risks and productivity of a line of research, with opportunities, or the interest of results, does indeed refer us to a market. But it is a market of positions where the commodity is scientists, and not a market for the products of free - or semi-free - entrepreneurs.

Scientists say of themselves: ${ }^{19}$

I went into this business with the idea of disproving hidden variables once and for all

and turn out to mean

I was looking for a postdoc position, or someplace to go when I finished my [PhD] thesis in astrophysics, and I wanted to do something in the foundations of quantum physics, although I really did not have anything in mind until I read about...

Who are the entrepreneurs in a system in which a scientist's ability to work, including the ability to raise money, may depend on decisions made at top organizational or other administrative levels? Let us listen once more to the biochemist (Holzman) I quoted before, when he talks not about his successful research strategies, but rather about his shifting positions in moving from one organization to the other: 
At the National Institutes of Health, I was under a guy who is in the same position I am today. In other words, I was at the lowest level and he was between me and the top echelons. So he trusted me, and he appreciated my work and he furthered it, and that's what is important. But people above him hardly knew what I was doing. The second one is CalTech. There, the person who was directly above me, the professor, had confidence in me, and a certain amount of admiration. He gave me a completely free hand.

When I came here, it was just the opposite. I was dumb-founded. You know, I was regarded with suspicion, and, uh, they cut off my funds, my equipment, I was all by myself. It was just like being in gaol...(9-29/5, emphasis added)

Or consider the following description of Holzman's move from the California Institute of Technology to the Center in Berkeley at which my observations were conducted:

...the money gave out, and maybe [the director's] predecessor was hostile, or developed a hostility, and they just said, 'That's it.' One day they came into the lab and said 'You are ready to pack up, aren't you? Come up to Berkeley.' I said, 'Why, what happened?', and they just decided one day that they couldn't afford my staying at CalTech. So it was an organizational decision. May be they actually were strapped for money. (9-29/6, emphasis added)

Incidentally, a change for the better in a scientist's organizational life does not change the underlying dependency of scientific work. Holzman described his 'sudden recognition' as follows:

I was greatly surprised yesterday. I had a meeting with $\mathbf{M}$ [the director] and the man has completely changed his ideas. I told him yesterday more or less what I told him when I first started here, and whereas at our first meeting he was full of contempt for all the stuff that I proposed, yesterday he was willing to listen. He encouraged me; he even suggested that I drop some stuff that I am doing that is more or less applied and that, in my opinion, is not worth doing.

Holzman had no explanation for the sudden change of opinion:

Well, he underwent a personality change (laughing). May be the ARS and the government in general have undergone a character change, the government is shaken up. (9-29/6)

It may be worth mentioning that Holzman held a top scientific position at the Laboratory (research leader), and is considered to be an internationally renowned scientist. The changes he mentioned at different points reflect the varying interest of his work for those who support it, and who consequently control his ability to work. 
The point here is that we may have to exchange the picture of the scientist-capitalist in a community of specialists for one which recognizes the basic dependencies of scientific work that lead us beyond these communities. If we do not take these dependencies into account, we will find it difficult to interpret such well-known phenomena as the structural unemployment of scientists in the United States and other countries, or the increasing unionization of scientists (including university scientists!). To be sure, there is one interpretation which considers scientific work primarily as wagedependent labour. However, the labour concept of scientific work has remained preoccupied with scientists' class affiliations, or, in the more bourgeois version of this perspective, with the role and socio-economic function of intellectuals in industrial society. ${ }^{20}$ Thus, with very few exceptions, the labour interpretation has left the content of science out of consideration. Moreover, where the content of science has been included in the picture (such as in SohnRethel's work), an a priori distinction between manual and intellectual labour has led to the same kind of decontextualization found in philosophers' characterizations of science. ${ }^{21}$ Intellectual labour is equated with abstract, quantitative thinking. Science emerges from Sohn-Rethel's analysis as social by origin and descent, but as thoroughly 'non-social' in terms of actual scientific inquiry, through the postulated character of intellectual labour.

\section{The Participant-Centred Perspective}

We have seen that the idea of a capitalist market mechanism operating within scientific communities sustains paradoxical assumptions of internalism and orthodox functionalism, and endorses a model of man which is at best simplistic. We have also seen that scientists' economic reasoning, when it does not simply express reasoned choice, points beyond specialty communities toward the basic dependencies of scientific work. What, then, is the conceptual status of this notion of a specialty community as employed in science studies? And what does it mean to substitute for the prevailing approach to the social and cognitive organization of science in terms of specialty groups a radically participant centred perspective on the contextuality of scientific work?

The first point to note is that the idea of a scientific community, or of a specialty community, refers to a logical class whose 
members (the specialists) are identified by characteristics attributed to them on the basis of sociological criteria. Thus, the concept of a specialty community is a typical example of an outsider's similari$t y$ classification, or to borrow a convenient term from linguistics, an etic concept. The distinction between 'etic' (from phonetic) and 'emic' (from phonemic) is used in linguistics and anthropology to denote the difference between 'context-free' (etic) descriptions of the real world (such as the analysis of colour provided by physicists), and 'context-specific' (emic) structural units and classes (such as those employed in folk-terminologies of colour). ${ }^{22}$ Here the distinction can be used to draw attention to the difference between taxonomic collectives ${ }^{23}$ which exist in the mind of the sociological classifier and those locally significant groups which appear to be relevant to the participants themselves.

Taxonomic collectives may have no real interrelations, and the similarities invoked by the sociologist to characterize their members may have no significance for participants themselves. Following Harré this can be taken to imply that taxonomic collectives may have no empirical referent, and that the use of terms which denote such collectives is prone to be of a rhetorical nature. ${ }^{24}$ This is not to deny that the notion of a specialist community has a function in certain theories related to the macro-organization of science - for example, in regard to professional associations. But it is to insist that the groupings proposed to be relevant in regard to scientific work should be of an empirical nature; that is, they should be meaningful in terms of participants' contextual involvements with a view to this work, and should not be based primarily upon externally imposed similarity classifications.

There has of course been a continual effort to specify specialist communities empirically in some areas of science studies, notably in citation and co-citation analysis. However, as Edge and other critics of this work have made clear, it is rather unlikely that citation clusters can be unproblematically identified with actual networks of intellectual indebtedness, whatever else they measure. ${ }^{25}$ Citation analysis blatantly neglects the literary and persuasive character of scientific texts and its consequences in regard to written presentations. Without doubt the social structure of citations in any set of scientific texts should be of considerable interest in the analysis of this literary character of science. Yet it can be shown that the social structure of citations does not preserve or even attempt to reflect the structure of actual interrelationships from 
which a particular scientific work emerges. ${ }^{26}$

Thus even when scientific communities have been conceived as intendedly empirical structures, the groups identified are better regarded as taxonomic collectives in the sense outlined above. At the very best they might be considered as theoretical entities whose existence and relevance outside the field of social studies of science must be hypothetical, and, as I shall argue shortly, whose definition is in any case incomplete. Yet there is a second sense in which perspectives which promote the search for scientific communities differ from the approach advocated here. I have in mind the distinction between macro- and micro-level perspectives, or between approaches which adopt a birds-eye perspective and those which start from the ground-level activities of participants. To specify the 'system' of science in terms of economic mechanisms operating within specialist communities is to exhibit from the start a macro-level interest in social structure. In contrast, the perspective advocated here insists that we specify social phenomena on a micro-level, and derive concepts of 'social structure' from the analysis of a multitude of micro-events. ${ }^{27}$ The point here is of course that statements about 'social structure' which are based upon statements about micro-level events may well look different from assertions about structure that are born out of detached macroperspectives. For example, they might include references to participants' own macro-representations, and pose the question what reality can 'social structure' possibly have apart from members' mutually related realizations? ${ }^{28}$

Let me stress that to advocate a more participant-centred perspective does not mean that participants' versions of social events are to be taken at face value. Nor am I involved with promoting a Winchean view of social science method as concerned with nothing more than the self-understanding of social agents. But aggregate procedures tend to neglect, and as a consequence to distort, the practical involvements and practical reasonings of agents. To avoid the accusation that they are no more than a sociologist's reification, statements of structure must have an empirical referent, which is the same as saying that they must include a specification of the mechanism by which structure emerges from, or relates to, observable micro-social action. 


\section{The Transepistemic Arenas of Research}

I am now in a position to offer a few tentative results from laboratory observations which I take to confirm the irrelevance, and indeed meaninglessness, of the notion of specialty communities in actual scientific work. Scientific work displays itself in the laboratory as traversed and sustained by relationships and activities which continually transcend the site of inquiry. How does this contextuality of scientific action manifest itself to the observer? We see scientists writing letters and sending out papers and grant proposals. We hear them talking to people all over the country on the phone, and we see them depart for visits to, and meetings at, a variety of places. We listen to their reports about those meetings, and we watch as grant proposals are modified and papers rewritten. We read the correspondence filed away in a folder and learn about contracts realized for industry, about raw materials being provided and samples exchanged. We question scientists about their trips, and correspondence and other activities which transcend the laboratory site, and we learn that they frame their scientific work in terms of their ex situ involvements.

Scientists make their laboratory work intelligible by referring to engagements and negotiations which point beyond the site of inquiry (and they make their ex situ involvements intelligible by reference to their laboratory work). But scientists' laboratory reasoning not only takes us outside the walls of the research site, it also takes us beyond the borders of the specialty under which a scientist - or a piece of research - comes to be classified. We are thus confronted with arenas of action which are transepistemic; they involve a mix of persons and arguments that do not fall naturally into a category of relationships pertaining to 'science' or 'the specialty', and a category of 'other' affairs. If we were to divide such an arena of action in terms of these categories we would be hard pressed to justify our demarcation.

Let me be more specific. The rewriting of a grant proposal with a view to the outcome of a scientist's visit to Washington usually involves more than changing the title. It involves reconceptualizing substantial parts of the content of the research planned. A scientist who realigns her or his research methods to match the orientation of the head of a department in which s/he has applied for a position effectively influences the outcomes of the research. And inquiries pursued or abandoned in accordance with the perceived response of 
the industry with which a contract exists can orient a whole research programme in one or another direction. In each of these cases, an external contact, a negotiation about money or a career strategy, has immediate technical repercussions.

Just as there is no reason to believe that the interactions between members of a specialty group are purely 'cognitive', there is no reason to believe that interactions between specialty members and other scientists or non-scientists are limited to money transfers or other exchanges commonly categorized as 'social'. Grant agents and industry salesmen may negotiate the appropriateness of a particular technical choice with a specialist, and specialty colleagues regularly discuss financial, personnel, and other 'non-scientific' decisions with each other in university departments and research institutes. The point here is that if we cannot assume that the 'cognitive' or 'technical' selections of scientific work are exclusively determined by a scientist's specialty membership groups, it makes no sense to search for a 'specialty community' as the relevant setting for knowledge production.

Scientific reasoning as observed in the laboratory cannot be reconciled with any partition between members of the relevant specialty community, on the one hand, and other scientists or nonscientists, on the other. The technical selections of the laboratory refer us to transepistemic arenas of action which are at the same time smaller and larger than the communities generally postulated in social studies of science. They are smaller in the sense that scientists' concerns evolve around a few central persons and arenas of operation which are actualized, transformed and renegotiated in direct or indirect communication. Relations with career-relevant senior scientists, with administrators, technicians, grant agents or publishers exemplify these involvements. But the respective arenas of transaction point to a larger constituency than the specialty group in that scientists engage not only scientists from other areas of research, but also non-scientists, as indicated earlier.

It is crucial to realize that the moves which are made in the various arenas of action need not add up to one particular game played according to a coherent set of rules in pursuit of a definite goal. The picture we get is more that of a field on which different games are played at the same time by a variety of people. The picture is not integrated by characteristics shared by those who play, as in the case of a logical class. Rather, the various games evolve from what is transmitted between agents in a succession of on- 
going, interlocking scenes. ${ }^{29}$ The field itself is 'theoretical' in the sense that it cannot be empirically identified independently of the social arenas in which the transactions take place. It is nothing more than the sum of interrelationships which the sociologist adopting a birds-eye perspective can reconstruct from agents' representations of their mutual involvements. As indicated earlier, this paper does not attempt such a reconstruction, which would presumably have to take the form of an empirically grounded (but not directly observable) network of interrelations. There are, however, at least two more issues which need to be raised in regard to transepistemic arenas themselves. The first concerns the nature of the symbolic relationships operative in these arenas, and the second (and perhaps most important) point concerns the relevance of the transepistemic connection of research to the production of knowledge.

\section{Resource-Relationships}

What is the nature of the symbolic relationships which obtain in a field of action that is seen to be integrated not by what is shared but by what is transmitted between agents? How do agents themselves construe their interchanges in the transepistemic arenas to which I have referred? On a most general level, these interchanges involve what is best called resource-relationships - that is, relations to which one resorts or on which one depends for supplies or support. Transepistemic arenas of symbolic action display themselves as the locus in which the establishment, definition, renewal or expansion of resource-relationships is effectively negotiated.

It is of course an underlying contention of much of the work on scientific communication that scientists depend on other scientists' work in their own scientific productions. Recently, Barnes has stressed that the historical significance of knowledge is that it acts as a resource which agents employ calculatively to further their interests; and Bourdieu has alerted us to the social and cultural resources ('capital') which scientists bring to bear upon - and collect from - their work. ${ }^{30}$ Thus, implicitly or explicitly, the notion of resources is central to social studies of science. However, I am not primarily concerned here with knowledge as a resource, or with the resources invested in the production of scientific results. The crucial point here is that we are talking about relationships, and 
that these relationships accommodate transactions among specialists and between scientists and non-scientists alike.

Let me develop this thesis by discussing the second aspect first. Resource-relationships as postulated here do not presuppose an a priori delimitation of the universe to which they apply. This means that the respective relationships are seen to be in principle similarly construed, whether they establish a link between scientists of the same specialty group, or between scientists and non-scientists, according to professional role and affiliation. An example of what appear to be intra-specialty resource-relationships is provided by Pickering's study of the recent acceptance of the charmonium explanation of certain newly discovered elementary particles in highenergy physics. ${ }^{31}$ The study illustrates how the charm model succeeded over rival explanations by generating a fresh stream of new soluble puzzles - that is, food for the continuation of normal science - and by vindicating previous scientific work which had utilized the quark concept. It appears that a majority of relevant high-energy physicists viewed the charm model as a resource they could convert into research work of their own, and discarded the alternative colour model because of its disconnected ad hoc explanations. The example accords with my own observation that scientists respond to suggestions by colleagues in terms of 'opportunities' - that is, in terms of the perceived unrealized capacities of a result to be inserted as a resource in the fabric of their ongoing research.

But there are other kinds of resource-relationships. Take the case of a post-doctoral researcher from India who told me he was being 'used' by the head of the laboratory on whom he depended for the continuation of his visa and contracts. The post-doc conducted all the research in a project, supervised students and technicians, and came up with ideas which were considered to be 'innovative'. His name appeared on papers but not on patents which resulted from the research, and it was the head of the laboratory who decided when and where to publish, and who presented the work at conferences. However, while the head of the laboratory was using the post-doc to 'run' the project, the post-doc was using the head of the laboratory to promote his own career. He came to the laboratory to get access to journals, research money and 'hot' research topics; and he thought that his affiliation with a prestigious institute would enable him to get a high-paying, high-prestige position upon returning to his country. In short, the post-doc appeared to use the head 
of the laboratory as a resource in his career project, while presenting himself as a resource needed by the head of the laboratory. The two parties involved monitored the resource-relationship so that the balance would be as favourable as possible to their interests. Other examples of what is involved in resource-relationships can readily be observed when academic positions are filled, when grant money is allocated to researchers, when speakers are chosen for a scientific lecture, and so on. For an academic institution, the selection of a candidate may depend on the degree to which s/he promises to be a resource which can be converted into other resources relevant to the institution (such as students and research money), or to the faculty who make the decision. For the foundation that awards a grant, this resource value may be defined in terms of the degree to which a research group can be trusted to engage in research whose funding and whose results can be justified in public. For the publishing house, publishing a book will depend on the degree to which the work or its author is perceived to be a resource in drawing an audience.

Notice that in all the cases mentioned, it is not some 'intrinsic value' of the research work which counts, but rather the convertibility of the prospective resource (whether a scientist or a scientist's work) into the locally relevant 'currencies' within which notions such as value or utility adopt their specific indexical meaning. Notice also that my insistence on talking about resourcerelationships entails that this convertibility is a continual and generally reciprocal accomplishment in at least three senses. First it is a continual accomplishment in the sense that what counts as a resource is itself at stake in these symbolic relationships. A reciprocal definition of something as a 'resource' is not stable, but a stabilization, to be endorsed by practices which sustain the definition. Second, resource-relationships must be continually renewed in order to survive. Consider the disproportionate amount of effort some research groups put into renewing their resource-relationships with financing agencies by writing research proposals. Finally, in a third sense scientists appear to be actively engaged in building, solidifying and expanding resource-relationships and in manipulating the convertibility of the resources at stake.

Thus, it is vital to realize that the interests which sustain the definition of something as a resource, the equivalence established between differently defined resources, and more generally the convertibility of resources, are themselves negotiated in resource- 
relationships. This means, for example, that we cannot unproblematically call upon somebody's interests to explain why something is perceived and adopted as a resource. ${ }^{32}$ From what was said before it will also be clear that resource-relationships are not conceived here in terms of goals which are shared by participants. Rather, they appear to emerge from a fusion of interests which are themselves subject to negotiation. It is tempting - but incorrect to view such interest fusions as marked by cooperation rather than conflict. In the case of the relationship between the post-doc and the head of his laboratory, conflict lurked behind the fragile balance achieved by interest-fusion, and surfaced whenever this balance broke down temporarily. Resource-relationships often link competitors in an area, or revolve around some other source of latent antagonism. Oscillations between conflict and cooperation, between the fission and fusion of interests that are reciprocally defined, are routine correlates of the process of negotiation which characterizes resource-relationships.

\section{The Transepistemic Connection of Inquiry}

I have said that scientific work observed in the laboratory continually refers us to transepistemic arenas of research, and that participants construe the symbolic transactions in these arenas in terms of resource-relationships. The question invited by these observations is of course how these transepistemic connections are relevant to the production of knowledge, and why they deserve much of the attention commonly devoted to specialty groups. Clearly, my quest for the contextual organization of science was not motivated by an interest in scientists' social relations apart from, and independent of, their work. Rather, it was an attempt to specify those contextual involvements which bear upon, or are an intrinsic part of, the production of knowledge as displayed in the laboratory.

Now I want to submit that scientists' transepistemic involvements are the locus in which the decision translations (the criteria) invoked by laboratory selections are defined, revised, and negotiated, in connection with negotiations over the resources at stake in various relationships. Take the case of a grant proposal. It has long been noted that 'problems' can be an 'external' input to scientific work, things which the wider social context passes on for treatment and cure within science. Funds are frequently earmarked for certain 
problem areas, and scientists are encouraged, should this be needed, to pick up on problems of general concern.

Yet funding agencies usually do much more than mark socially desirable goals. The proposals I looked at consist of chains of problem translations which start from a definition of purpose and continue through fine grained elaborations of methods, source materials and processes. It is exactly through these elaborations that financing agencies and scientists negotiate what the problem is, and how it is to be translated into actual research selections. To refer to research problems as an 'external' input to science is to ignore the process of elaboration which penetrates into the very core of scientific work. Grant agencies, or government and industry contractors, are directly involved in this process, through proposing or preventing problem translations linked to the decision criteria employed in the laboratory.

Elsewhere I have proposed that scientific inquiry displays itself in actual scientific work as constructive rather than descriptive, and I have specified constructivity in terms of the decision-impregnated character of inquiry work. ${ }^{33}$ Accordingly, scientific work consists of the continued realization and thematization of selectivity, which means that the selections realized in previous scientific work become both topic and resource for further scientific investigations. Selections can only be made on the basis of other selections; that is, they require translations into further selections, the socalled 'decision criteria'. For example, the seemingly simple choice between a filter and a centrifuge to separate certain substances may become translated into choices which invoke the different duration of the processes, the accessibility of equipment, or the different energy costs implied. Scientific products are highly structured internally in terms of strata of selections, in addition to whatever 'external' structuring they possess through some match or mismatch with 'nature'.

Now the thesis here is that the constraints into which laboratory selections translate, and the relationships which nourish these constraints, are negotiated in the transepistemic arenas in which scientists are involved; that is, they refer us to transepistemic fields of symbolic transaction rather than to scientific fields or communities of specialists. To be sure, scientific work consists to a substantial degree in actually making (as well as foreseeing, planning or reconstructing) the respective selections. Yet this does not mean that these decisions, and consequently the resulting 
laboratory constructions, are independent of the transepistemic contextures to which we are referred. Having control over a decision is not the same as having control over the necessary translations involved, and it is through these translations of decision criteria that the transepistemic connections of research are maintained. It is here that the commitments and interests negotiated in transepistemic arenas are invoked and taken into consideration, and that consistency with requirements imposed by resourcerelationships is built into scientific results.

Needless to say, only selections which become of topical interest lead to translations in which choices are made explicit. Many laboratory selections are made routinely, without ever becoming topics of discussion or reflection. Scientists speak of such selections as the 'normal', 'natural' or 'logical' thing to do. This implies that the frozen selectivity incorporated in the normal course of scientific action will not be noticed, unless something interferes with the 'natural' sequence of events.

But there is another point which needs to be emphasized before concluding this paper. To postulate a connection between the scientists' contextual involvements and the selections of the laboratory mediated by decision criteria is not to suggest that we can read off these criteria from specific contextual involvements. Commitments negotiated, and elaborations of research problems anticipated, in transepistemic interactions may become renegotiated in actual laboratory work, and decision criteria embodied in these commitments may become revised, ignored or overthrown in the process of inquiry. Furthermore, when there is a fusion of interests brought about by resource-relationships, their impact on research decisions may be ill defined. To achieve consistency of scientific results with the context in which they are situated is a problem for the scientists themselves. Scientists 'figure', 'gather', 'think' and 'hope' that a particular problem translation, a technique chosen, or a product construed in laboratory work will match the interest of those to whom they are committed, but they often do not know exactly what is expected from them. So they redirect their guesswork according to the responses they get, and they may end up convincing those who are 'interested' in the work about what exactly they should be interested in.

It is important to appreciate this indeterminacy as crucial to the occurrence of new information. If the selections of the laboratory could be predetermined by a set of specific criteria effective under 
specifiable conditions, research would be reduced to a preprogrammed execution of the respective conditions. Thus, the issue is not to deplore the existence of the indeterminacy which prevents us from predicting research decisions, but to see it as a condition of the possibility for the increase of information. According to information theory, an optimum of information cannot obtain when two subsystems linked are either totally dependent or totally independent of each other. Rather, it emerges from a non-zero transmission of information between the systems and a certain amount of error in the transmission. ${ }^{34}$ It is in this sense that indeterminacy (corresponding to some error, or our inability to read off laboratory selections from the scientists' transepistemic involvements) can be seen to enable or occasion the occurrence of new information.

\section{Conclusion}

To conclude let me stress that there is of course nothing new in postulating a substantive connection between the constructions of science and other areas of social life. Historians of science have deduced such connections from overlapping developments within and outside of science, and sociologists of knowledge have sought to provide theoretical conceptions of the problem (though only recently in regard to the natural sciences). In general, these studies appear to have proceeded by identifying similarities between ideas expressed in scientific theories or other products and modes of thinking or behaviour found in social practice. As an example, consider the affinity postulated by Sohn-Rethel between the Galilean concept of inertial motion and the abstractness of commodity exchange in everyday economic transactions. However, such similarities, which are often attributed to shared worldviews or shared class interests (Mannheim's Interessenslagen), are all too easily called into question, particularly if the mechanisms through which the alleged correspondence comes about remain obscure or are difficult to vindicate empirically. ${ }^{35}$

In contrast to the congruence approach, the suggestion I have offered points toward a genetic approach to the transepistemic connections of research. The argument from laboratory observations is that the transepistemic connections of research operate through decision translations negotiated in transepistemic arenas of action. 
Thus, laboratory observation locates the problem in the process of knowledge production. It suggests that this process is constructive (decision-impregnated), and identifies the resource-relationships in which scientific work appears to be inserted as the vehicle of transepistemic connections. In particular, it is the specific contention of this paper that the transepistemic connections of research as they display themselves in the laboratory challenge our tendency to fall back upon the notion of specialist communities as the relevant contextures of the social and cognitive organization of scientific work. Scientific work appears to be inserted in contextures which, by nature and necessity, point beyond the specialty areas under which the bookkeepers of scientific life may classify a piece of work. Paradoxically, it is the internal working of science which demonstrates that the internalism entailed by our concern with scientific communities or specialty fields may finally need to be rejected.

NOTES

I am grateful to John Law and Sal Restivo for comments and editorial suggestions (including the notion trans 'epistemic' which I owe to Restivo's interpretation of this work). I should like to thank all scientists who gave up their time to this research.

1. The examples and arguments presented in this paper draw upon one year of observations (1976-77) with a group of scientists working on plant proteins at a government-financed Research Center employing more than 300 scientists (along with technicians and laboratory assistants) in Berkeley, Calfornia. Most of the scientists hold degrees in biochemistry and in one of the chemical, physical microbiological, toxicological, technological and economic areas in which the Center conducts research. For a more detailed account of the study, see K. KnorrCetina, The Manufacture of Knowledge: An Essay on the Constructivist and Contextual Nature of Science (Oxford \& New York: Pergamon Press, 1981).

2. R. Whitley, 'Black Boxism and the Sociology of Science,' in P. Halmos (ed.), The Sociology of Science, Sociological Review Monograph No. 18 (Keele, Staffs.: University of Keele, 1972), 66-92.

3. Although they do so under different titles, I have generally used the notions of indexicality, opportunism, and situational contingency to refer to the phenomenon. Others have referred to the importance of milieu, to local disorder, or to the circumstantial nature of research. See and M. Zenzen and S. Restivo, 'The Mysterious Morphology of Immiscible Liquids: A Study of Scientific Practice' (Troy, NY: Department of Anthropology and Sociology, Rensselaer Polytechnic In- 
stitute, 1981, unpublished mimeo); B. Latour and S. Woolgar, Laboratory Life: The Social Construction of Scientific Facts (Beverly Hills, Calif.: Sage, 1979), 235ff; Latour, 'Is it Possible to Reconstruct the Research Process?', in K. Knorr, R. Krohn and R. Whitley (eds), The Social Process of Scientific Investigation, Sociology of the Sciences Yearbook, Vol. 4 (Dordrecht, London \& Boston, Mass.: D. Reidel, 1980), 53-73; Knorr, 'Producing and Reproducing Knowledge: Descriptive or Constructive? Toward a Model of Research Production', Social Science Information, Vol. 16 (1977), 669-96; as well as Knorr, 'Tinkering toward Success: Prelude to a Theory of Scientific Practice', Theory and Society, Vol. 8 (1979), 347-76; and op. cit. note 1 , Chapter 2.

4. For representative studies see W. Hagstrom, The Scientific Community (New York: Basic Books, 1965); M. Mulkay, G.N. Gilbert and S. Woolgar, 'Problem Areas and Research Networks in Science', Sociology, Vol. 9 (1975), 187-203; P. Bourdieu, 'The Specificity of the Scientific Field and the Social Conditions of the Progress of Reason', Social Science Information, Vol. 14, No. 6 (1975), 19-47; or the studies collected in G. Lemaine, R. MacLeod, M. Mulkay, and P. Weingart (eds), Perspectives on the Emergence of Scientific Disciplines (The Hague: Mouton, and Chicago: Aldine, 1976).

5. The circumscription of these specialty areas is of course a key concern of citation studies. For recent, critical reviews of these efforts, see D. Edge, 'Quantitative Measures of Communication in Science: A Critical Review', History of Science, Vol. 17 (1979), 102-34, and S. Woolgar, 'The Identification and Definition of Scientific Collectivities', in Lemaine et al., op. cit. note 4, 233-45.

6. R. Whitley, 'Types of Science, Organisational Strategies and Patterns of Work in Research Laboratories in Different Scientific Fields', Social Science Information, Vol. 17 (1978), 427-47, at 427; Edge, op. cit. note 5. For a trans-cultural concept of scientific activities see S. Restivo and C. Vanderpool, 'The Third-Culture of Science', in Restivo and Vanderpool (eds), Comparative Studies in Science and Society (Columbus, Ohio: Charles E. Merrill, 1974), 461-72.

7. For a more extensive review of the use of the idea of competition in recent sociology of science, see $M$. Callon, ' $L$ 'operation de traduction comme relation symbolique', in M. Roqueplo (ed.), Les incidences des rapports sociaux sur la science (Paris: CORDES, 1975), 105-41.

8. Hagstrom, op. cit. note 4; N. Storer, The Social System of Science (New York: Holt, Rinehart \& Winston, 1966).

9. Bourdieu, op. cit. note 4.

10. Op. cit. note 3, Chapter 5. The most coherent and pertinent presentation of this model is found in an unpublished paper by B. Latour, 'Le dernier des capitalistes sauvages: Interview d'un biochemiste' (Paris: Conservatoire des Arts et Metiers, 1979). The model has recently been employed by J. Law and R. Williams, who do, however, go beyond the credibility concept, recognizing that "calculations about credibility rarely take place uninfluenced by non-credibility issues... . To view science as the disinterested search for credibility is, in its own way, as misleading as to view it as the disinterested search for truth'. See Williams and Law, 'Beyond the Bounds of Credibility', Fundamenta Scientiae, Vol. 1 (1980), 295-315, quote at 313; and Law and Williams, 'Putting Facts Together: A Study of Scientific Persuasion', Social Studies of Science (forthcoming). Consider particularly the latter paper for its hints at a 'network' model which transcends the credibility model.

11. See also my own use of Bourdieu's model, in which I attempted to combine a 
constructivist interpretation of science (with the notion of success as a guiding principle of laboratory action), and Bourdieu's notion of a scientific field, into a first sketch of what led to my present conception: Knorr 1977, 1979, op. cit. note 3.

12. Following the early work of Simon, rational models of decision making were replaced by alternative conceptions. For a recent example, see J. March and J. Olsen, Ambiguity and Choice in Organisations (Bergen; Universitet forlaget, 1976); and, of course, the classic work by J. March and H. Simon, Organizations (New York: Wiley, 1958).

13. The concept of 'habitus' is best expounded in P. Bourdieu, Outline of a Theory of Practice (Cambridge: Cambridge University Press, 1977).

14. E. Goffman, 'The Neglected Situation', in P.P. Giglioli (ed.), Language and Social Context (Harmondsworth, Middx.: Penguin, 1972), 61-66, quote at 63.

15. See, for example, Latour and Woolgar, op. cit. note 3, 207. On the other hand, the original question is posed in terms of 'What motivates scientists?' (189), which I take to be an example of the inconsistencies which necessarily follow from employing concepts which refer to individuals (such as investment and credibility) on a macro-level.

16. See the hint of a similar underlying criticism in Williams and Law's reflection on the credibility model quoted in note 10 .

17. For a more extensive documentation of the following examples see the reference in note 1. Quotations from the laboratory notes are indexed by the month, day and page number of the observation protocol: eg. (9-24/4) comes from page 4 of the protocol of 24 September 1977.

18. In particular, see Latour, op. cit. note 10; Williams and Law, op. cit note 10; Knorr-Cetina, op. cit note 1, Chapter 4; and B. Harvey, 'The Effects of Social Context on the Process of Scientific Investigation: Experimental Tests of Quantum Mechanics', in Knorr, Krohn and Whitley, op. cit. note 3, 139-63.

19. These statements are taken from Harvey's interviews with scientists involved in the experimental test of quantum mechanics, with my emphasis added. See Harvey, op. cit. note $18,145,147$. Harvey documents these scientists' concern with their careers as an integral part of their choice of research topics and other cognitive moves.

20. For an example, see A. Gouldner, The Future of Intellectuals and the Rise of the New Class (New York: Seabury Press, 1979).

21. See A. Sohn-Rethel, 'Science as Alienated Consciousness', Radical Science Journal, No. 2/3 (1975), 72-101, for a summary of this position.

22. For an outline of the emic vs etic debate in anthropology, and for a presentation of the issues involved, see W.C. Sturtevant, 'Studies in Ethnoscience', American Anthropologist, Vol. 66, No. 3, Pt. 2 (1964), 99-131, esp. $101 \mathrm{ff}$.

23. See the discussion of taxonomic collectives by $R$. Harré, 'Philosophical Aspects of the Micro-Macro Problem', in K. Knorr-Cetina and A. Cicourel (eds), Advances in Social Theory and Methodology: Toward an Integration of Micro- and Macrosociologies (London: Routledge and Kegan Paul, 1981), Chapter 4.

24. Ibid., particularly the section on macro-social concepts as rhetorical devices, $148 \mathrm{ff}$ and $156 \mathrm{ff}$.

25. Edge, op. cit. note 5 .

26. For an analysis of the transformations which scientific work undergoes as we move from the laboratory to the scientific paper, see G.N. Gilbert, 'The Transformation of Research Findings into Scientific Knowledge', Social Studies of Science, 
Vol. 6 (1976), 281-306, and K. Knorr and D.W. Knorr, 'The Scientist as a Literary Reasoner', in J. O'Neill (ed.), Science Texts (forthcoming, 1982). The latter study illustrates the almost total disappearance of the network of agents and relationships into which scientific work is inserted in the laboratory from the written text, and the substitution of a network of intra- and inter-specialty relations.

27. This is one of a few major divides between the 'ethnography of knowledge' approach I advocate here and the recent upsurge of sociology of knowledge outlooks on science promoted and best represented by B. Barnes. For a statement that the imputations made by the latter approach are sought for and lie on a structural level, see, for example, Barnes, Interests and the Growth of Knowledge (London: Routledge and Kegan Paul, 1977), 61. See also, in general, D. Bloor, Knowledge and Social Imagery (London: Routledge and Kegan Paul, 1976). I hasten to add that my rejection of our notion of, and continued focus on, scientific communities, which is born out of the grounded theorizing implicated in laboratory observations, is not only perfectly compatible with the sociology of knowledge outlook on science, but indeed sustains such a perspective.

28. The difficulty for the macro-theorist is of course how to avoid the charge of reification, and the difficulty for the micro-theorist appears to be how to avoid the charge of subjectivism and idealism. However, this is not the place to enter a discussion of these hoary old philosophical and methodological puzzles. Suffice it to say that those inclined toward an unashamed empiricism must somehow come to base their macro-constructions on micro-foundations. Or how are we to justify our macro-observations if not by tracking them down, in the final analysis, to the microepisodes of which social life consists?

29. The underlying idea here is that common characteristics, like common culture or common language, depend upon the interaction of those who 'share' it. Thus, they must be seen as consequences of what is transmitted - and thereby perhaps continually renewed - between agents. As Bloomfield had already noted in 1933, 'the most important differences of speech within a community are due to differences in density of communication'. What holds for speech surely also holds for other aspects of culture. See L. Bloomfield, Language (New York: Henry Holt, 1933), 46.

30. See, for example, Barnes, op. cit note 27, 16, 30, 81; and Bourdieu, op. cit. note 4.

31. Cf. A. Pickering, 'The Role of Interests in High Energy Physics: The Choice between Charm and Colour', in Knorr, Krohn and Whitley, op. cit note 3, 107-38.

32. This is a second major divide between the ethnography of knowledge approach taken here and the 'interests model' pursued by the sociology of knowledge outlook on science. Now I do not suggest that we cannot attempt to explain social action naturalistically in terms of interests; this is, after all, what every one of us continually does in everyday life. But such explanations must somehow come to grips with the problem (a) that these interests are not generally obvious to agents themselves; (b) that interests, like other phenomena, appear to be negotiated and accomplished in social action rather than to simply 'exist'; (c) that 'objectively' attributed and 'subjectively' perceived interests do not always coincide; which means (d) that there is a question as to who may or may not legitimately identify somebody's interests, and on what grounds. While some of these questions, and others, have been admirably addressed in the Marxist interests model, they surely cannot be said to have been resolved. For a slightly different critique of the interest model, see S. Woolgar, 'Interests and Explanation in the Social Study of Science', 
Social Studies of Science, Vol. 11 (1981), 365-94. For illustrations of the interests model which has, despite the above difficulties, given rise to several challenging case studies, see again Barnes, op. cit. note 27; Pickering, op. cit note 31; D. MacKenzie, 'Statistical Theory and Social Interests: A Case Study', Social Studies of Science, Vol. 8 (1978), 35-83; MacKenzie and Barnes, 'Scientific Judgement: The Biometry-Mendelism Controversy', in Barnes and S. Shapin (eds), Natural Order: Historical Studies of Scientific Culture (London \& Beverly Hills, Calif.: Sage, 1979), 191-210; and Shapin, 'Homo Phrenologicus: Anthropological Perspectives on an Historical Problem', ibid., 41-71.

33. Cf. Knorr-Cetina, op. cit. note 1, Chapter 1.

34. For a summary of the arguments which substantiate the creation of 'organization out of chance', or 'order out of disorder', according to recent developments in thermodynamics and information theory, see $\mathrm{H}$. Atlan, Entre le cristal et la fumée (Paris: Seuil, 1979), particularly the example on p. 47.

35. See, for example, B. Young's critique of the similarity invoked by SohnRethel, in his Introduction to Sohn-Rethel, op. cit. note 21. Or consider Norton's critique of the homology postulated in Barnes and MacKenzie's study (op. cit. note 32) between Pearson's conception of evolution as an incremental process amenable to gradual redirection and strands of reformist, interventionist thinking attributed to the rising professional middle class: B.J. Norton, 'Karl Pearson and Statistics: The Social Origins of Scientific Innovation', Social Studies of Science, Vol. 8 (1978), 3-34, at 30 .

Karin D. Knorr-Cetina is Associate Professor of Sociology currently developing a graduate programme in Science Studies at Virginia Tech and State University. Her present work includes a focus on the production of knowledge as studied through direct ethnographic observation and on the relation between micro- and macrosocial phenomena in science and other areas of social life. Her book The Manufacture of Knowledge: An Essay on the Constructivist and Contextual Nature of Science (Oxford: Pergamon, 1981) is a first comprehensive report of the former work. The second focus of her work is reflected in the book Advances in

Social Theory and Methodology: Toward an Integration of Micro- and Macrosociologies, which she edited and introduced with Aaron Cicourel (London: Routledge and Kegan Paul, 1981). Author's address: Center for the Study of Science in Society, Virginia Tech and State University, Blacksburg, VA 24061, USA. 